\title{
Why Ethics? Towards Understanding the Ethical Practices of Academic Program Heads
}

\author{
Abel V. Alvarez, Jr., Laira Janelle Contreras, Rogelio Abrantes, Jr., Dan Russell Ventura, \\ Katty Villariasa, Lovely Corcuera, Reuben Ramiro Natividad, Mina Samortin, \\ Aida Gabionza, Lenie flor Lot, Christina Rodriguez, Jiaxin Chen \\ Far Eastern University, Manila, Philippines
}

\begin{abstract}
The purpose of the study is to determine the ethical practices applied by academic program heads and their implication to academic development of the university. It further aims to explore the significance of ethical practices in the development of the academe and how academic program heads practice ethics in order to enhance the program of the institution. The study was conducted using a qualitative, case study research design. The participants were selected purposively, and out of 22 academic program heads, only 13 were able to participate due to conflict with their schedule and academic related operations. The data was collected using questionnaires, interviews and field notes. All thirteen academic program heads demonstrate a strong commitment to perceive and interpret reality within the context of honesty and openness. Next, they are able to create reality by continually reaffirming the ideals and beliefs of their respective organizations. They are also particularly concerned on how their decisions affect other people. In fact, the participants recognize that midlevel decision-making have also great impact in which can affect its colleagues. From the perspective of personality, program heads possess an exceptionally strong motivation and are emotionally strong, courageous, and fair in treating all co-workers and students justly with temperance. Finally, it was revealed that academic program heads value their moral commitment which is rooted on their religious faith and beliefs; hence, it directs their decisionmaking management.
\end{abstract}

\section{Introduction}

In the recent years, there is a rapid growth of attention in ethical practices of academic leaders. One of the leading non-sectarian institution in the Philippines, which for the purpose of this research will be named as university $\mathrm{X}$, has six flagship colleges namely: Accounts, Business, and Finance, Arts and Sciences, Architecture and Fine Arts, Education, Tourism and Hotel Management, and Nursing. It offers undergraduate and graduate degree programs in response to society's needs and demands. Weegar [1] pointed out the significance of ethical standards in ensuring the university's operation. It is bounded within the law and is seen as an ethical institution of learning by the community. Primarily, this reflects the idea that educational institutions must take the lead towards the promotion of ethical practices in today's learning society.

In university $\mathrm{X}$, the mid-level academic managers, specifically the program heads, play an essential role in the development and operation of department's day-to-day activities. Program heads are considered as core and soul of the university's academic units. Considering the mandate of Commission on Higher Education, the university is expected to function in trifocal system - instruction, research, and extension. Hence, university X program heads have huge ethical responsibility in taking charge of the academic functions and operations.

Basically, they act as academic front liners as they are the first persons who address the needs of stakeholders in the university - faculty, students, parents, etc. They also serve as academic implementers when it comes to the university and institute's academic policies, assessment and evaluation of student learning outcomes, facilitation and conduction of faculty and student orientation and training programs, and providing academic advising and other forms of student support programs.

In addition, they are considered as policymakers in the department level. As a policymaker, they are tasked to craft program guidelines and unit protocols. Internship procedures, for instance, is one of the essential responsibilities of program heads to ensure that faculty affiliates and students are guided accordingly prior to company and/or clinical exposure. Another is when it comes to research protocols. In the undergraduate level, for example, some program heads require their students to at least work in triad, whereas others are organized into at least 6-8 members per group. There are also some programs that oblige undergraduate students to undergo oral defense before proceeding with data gathering. Further in graduate level, most program heads are requiring their graduate students to have course research paper requirements.

Meanwhile, in terms of protocols, each department has specific academic office operations.

For example, office forms and processes are conceptualized and designed by unit heads for their daily operations and transactions. Academic 
leadership and practices, therefore, are integral in the mobilization of academic programs and activities of schools. In relation to this, Mihelič, Lipičnik, and Tekavčič [2] stress out that leaders are "crucial source of ethical guidance for employees and should at the same time be responsible for moral development in an organization" (p. 31).

In fact, there was a study conducted by Catacutan and De Guzman [3] wherein they revealed that "the deans articulated their views on the goals of education as the achievement of individuals' self-realization, and considered their role as educators in contributing to the development of their students' human potential as the rationale behind administrative decisions framed from an ethic of care perspective" (p.504). Likewise, Emery [4] clearly emphasizes that leaders in the organizations have enormous duty to ensure the highest standards of ethical conduct. Thus, this can be associated with the way academic leaders handle and manage various ethical practices which can influence the academic development of the institution as well as its stakeholders - faculty and students.

Program heads, as educational leaders play a critical role in the improvement of the performance and quality of institutions and individuals [5] [6] [7]. They lead, manage and ensure that all of the activities of their department are being accomplished to the highest possible level of excellence. Necessary support, then, should be given to teachers and staff to enable them to contribute to the growth of the institution as well as to deliver quality education to students.

Foster [8] explained that, "each administrative decision carries with it a restructuring of human life: that is why administration at its heart is a resolution of moral dilemmas". Leadership becomes a moral issue for educators because of their social responsibility to their students. While it is true that the set values of a child come from his family, his concept of morality is polished in school, especially in tertiary. Teachers are great influencers. Students emulate the ideals and values of their teacher, especially those they look up to. On the other hand, teachers perform their duty in accordance to the principles and policies set by the program head. Polies and principles based on the system of values, or deeply held beliefs, that served as the ethical framework from which a leader develops a vision, defines and shapes the change process, and takes actions to make his or her vision a reality [9].

Decision-making which is an integral part of leadership relies on how program heads define what are wrong and right for him. Doing the "right thing" would be determined by whether the action fulfilled a duty to others, did not infringe upon the rights of others, benefitted others, and was virtuous in itself [10]. It opposes the Machivellian approach of the ends justifying the means. The greatest common good must always prevail, however for an ethical leader it should not be at the cost of compromising his dignity and morality.

Shapiro and Stefkovich [11] discuss numerous paradigms for the analysis of ethical behaviour which encompasses ethics of justice, critique, care, and profession. Ethic of justice provides an analytical and rational approach to judging human behaviour and interactions. It promotes "commitment to human freedom" and "procedures for making decisions that respect the equal sovereignty of people" [34]. In resolving issues between two parties, rules should be administered fairly and clearly [35] in order to create a positive climate between the faculty and administration and even with faculty and students.

The ethic of critique addresses the inequities among individuals and groups related to social class and other factors which impact one's power and voice, as well as the ensuing treatment, resources, and other benefits. It "asks educators to go beyond questioning and critical analysis to examine and grapple with those possibilities that could enable all children, whatever their social class, race, or gender, to have opportunities to grow, learn, and achieve. Such a process should lead to the development of options related to important concepts such as oppression, power, privilege, authority, voice, language, and empowerment," according to Shapiro and Stefkovich [11].

Additionally, a fourth ethic of profession which integrates the other three ethics, based on an educational leader's examination of his or her own values and the ethical codes set forth by various professional organizations, so that the best interest of the students should be foremost in determining the actions taken by educational leaders [11]. While, Catacutan and De Guzman [3] emphasize that the Philippine society has become aware of contemporary ethical issues and their impact to learning environment. As such, in university $\mathrm{X}$ context, the program heads play an important role in the mobilization of academic decision-making practices and leadership of the institute faculties. They exercise leadership over faculty, staff, and students. They provide administrative and academic assistance and supervision in the management of their respective program department.

This will be beneficial to program heads as it will serve as determinants of their ethical practices in terms of dealing with their faculty, students, and the institution. Likewise, this will serve as basis for school leaders to reflect their administrative management over faculty, students, and staff when facing ethical dilemmas and ethical decision-making. While for school administration, this will provide the institution a basis for monitoring and evaluation of academic and administrative ethical practices of middle management level. To further articulate the point, this paper will explore the ethical practices of 
academic program heads in dealing with ethical dilemmas and ethical decision-making.

\section{Conceptual Framework}

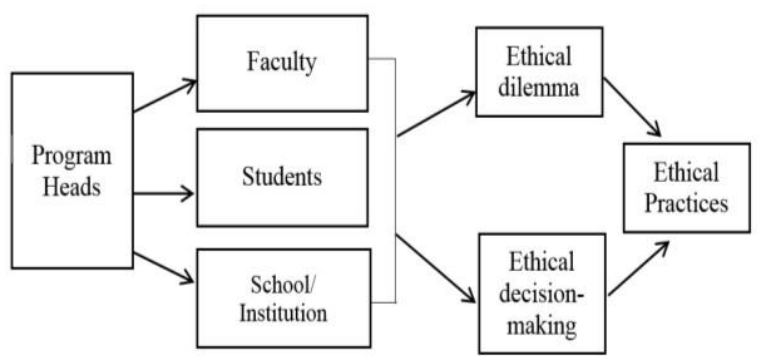

Figure 1: Research paradigm of ethical practices

\section{Statement of the problem}

The study sought to determine the ethical practices of university X program heads; specifically, it sought to answer the following questions:

i. What are the common ethical practices of university X Program Heads in relation to their faculty, students, and the institution?

ii. What ethical practices are applied by the Program Heads when faced by ethical dilemma and ethical decision-making?

iii. What are the experiences of university X Program Heads during ethical dilemmas and ethical decision-making?

\section{Methodology}

The study was conducted at university $\mathrm{X}$ in Manila, Philippines and the chosen participants are the Program Heads of each Degree Programs that the University offers. The rationale behind this is because the researchers would like to identify if the ethical practices of the Program Heads contributes to the academic development of the University.

There are six institutes with twenty-two programs handled by various program heads in the university. Participants of this study are considered appropriate population because the researchers believe that they are the best sources who will give the necessary and important details needed in the research. Therefore, they are in the best position to provide information needed by the researchers to answer the research questions of the study.

The sample population of the study comprises of eleven Programs Heads in Institute of Arts and Sciences, two in Institute of Nursing, three in Institute of Accounts, Business and Finance, two in Institutes of Architecture and Fine Arts, two in Institute of
Tourism and Hotel Management, and two in Institute of Education with the total of twenty two participants.

Thus, a short answer survey was given to the 22 Program Heads of the University and only 13 Program Heads responded. The following questions were given to evaluate the ethical practices of each participants:

i. was there any instance where your attention was called because of a perceived "unethical practice"?

ii. how do you deal with personnel/students with perceived to display unethical behaviour? How do you resolve such issues?

iii. how do you practice ethical behaviour in your workplace?

iv. how do you come up with ethical decisions?

v. how do you live out the university $\mathrm{X}$ Core Values of Fortitude, Excellence, and Uprightness? Please cite an instance. The researchers interpreted the given output afterwards.

Data were analysed using themes developed from the descriptions of the shared experiences of the participants. Basically, it was used in order to investigate a phenomenon or a particular experience of each respondent and the effect of it. According to Willis and Nilakanta [12], phenomenology is focused on the subjective reality. It needs to point out the subjective view of the participants about themselves and the world.

\section{Findings and discussion}

This section discusses the findings of the study. It also includes the interpretation and analysis of gathered data using thematic approach. The narrative discussions of the findings are illustrated in tabular presentation for better illustration of interpretation and analysis of the information. To address the first research question about instances where program heads' attention was called due to perceive unethical practices, it was revealed that 11 out of 13 participants have not experienced being called for perceived unethical practices as academic managers. In the contrary, results showed that academic dishonesty and misbehaviour are two considerations of unethical practices that caught their attention.

P8 emphasized cheating and lying as form of academic dishonesty. In fact, P8 was summoned to address students' unethical action, considering it can affect the institution's academic integrity. It was revealed by Arnett, Arnett, Feldman, and Cauffman 
[13] that students' involvement in academic dishonesty, such as cheating on tests, copying of assignments, and plagiarism, increases over time. In addition, academic dishonesty, at all levels, consistently becomes a problem of many schools, specifically there is steadily increase of cheating incidence among college students over the past forty years [14]. As such, the impact of this unethical practice of academic dishonesty in school context can also be attributed to "poor job of policing" by professors [15].

Meanwhile, P8 and P10 shared both unethical practices they experienced. P8 calls the attention of students because of their class behaviour such as absenteeism and tardiness. Kearney [16] stated that absenteeism can be due to medical illness or injury (excusable) or environmental, social, or other conditions (inexcusable). It was also discussed by the National

Center for Education Statistics (199-2000 as cited by Kearney [16] wherein $32 \%$ of principals and teachers stated that tardiness is also a common problem in schools. Further, findings showed that absenteeism of students can also be caused by financial issues [3].

Likewise, P10 recalled the incident of an instructor who required students to have a special project which is beyond the prescribed course requirement. Thus, Catacutan and de Guzman [3] revealed in their study that one of the common ethical dilemmas faced by academic managers are concerned with faculty's conflict of interests.

For the questions, how do you deal with personnel/students with perceived to display unethical behaviour? How do you resolve such issues? results shown that $\mathrm{P} 1, \mathrm{P} 2, \mathrm{P} 3, \mathrm{P} 7, \mathrm{P} 10$, and $\mathrm{P} 13$ respond to unethical behaviour employ by their personnel / students by aligning their ethical decisions to organizational code of conduct or policies. They pointed out the idea of having thorough investigation by gathering evidence, office referrals and endorsement as stipulated in the school's code of conduct. Bray [17] discussed that code of conduct can be associated to societal law where there is norms, values, and rules accepted by community as its law; citizens or bearers of rights and duties that require to follow certain rules and regulations. Resolving ethical dilemmas by relying on code of conduct, therefore, will help academic managers be guided in their ethical decision-making and improve academic services to its stakeholders [18]. As such, the notion of direct approach of codes of conduct where also explained as something that assumes a central role and is identified and prescribed towards addressing unethical behaviour [19]. Hence, for P1, P2, P3, P7, P10, and $\mathrm{P} 13$, they respond to these unethical behaviours/actions based from the organizational code of conduct in which it serves for promotion, maintenance, and enforcement of discipline as well as restoration of order in the school setting [17].

Moreover, P2 considered minor offenses as something that can be done through reprimands, involvement in community service, and/or summoning of parents. There was a study conducted by Mumthas, Munavvir and Abdul Gafoor [20] in terms of the use of disciplinary practices by teachers wherein $11.70 \%$ are using reprimand as means of responding to unethical behaviours, and $9.70 \%$ are being provided with other responsibilities which, for instance, can be attributed to community services in school; whereas, $4.80 \%$ of students stated that teachers inform their parents for their unethical behaviour.

Furthermore, mostly of the participants described their experiences in resolving unethical behaviour through dialogue involvement. P2, P3, P4, P5, P6, P8, $\mathrm{P} 9, \mathrm{P} 10, \mathrm{P} 11, \mathrm{P} 12$, and $\mathrm{P} 13$ believed that discussion with the concerned personnel/students are essential intervention rather than addressing the unethical dilemmas by means of "direct approach of codes of conduct" [19]. In addition, discussions or dialogue with students, and perhaps with personnel, revealed an increase sense of competency and belonging leading to having a decrease misbehaviour involvement [21]. In fact, it was argued that dialogue is essential in addressing unethical behaviour because it serves to develop new understanding Gottlieb and Sanzgiri, as cited by [22] when it comes to the organizations policies and protocols

Meanwhile, in answering the question about the way program heads' practice ethical behaviour particularly in the workplace, findings revealed that P3, P4, P5, P7 and P11 primarily answer the question in accordance of code of conduct. They lay out an organization's expectations and guiding principles for appropriate workplace behaviour. Sebisha [23] discussed that Conduct reflects the behaviour, acts and omissions, and attitudes of individual in an environment, and a code of conduct serves to create an environment in which individual behave with tolerance, appreciation and respect for one another.

Participants 1, 4, 5, 6, 9, 10 and 13 made mention diligently observe the policies, rules and regulation of the institution. These adhere to the rules of workplace, such as the policies within the company, to function effectively. It is important for an institution to be able to motivate effectively rule following behaviour among employees. Tyler [24] emphasizes that organizational rules and policies stipulate desired employee behaviour, and the organization benefits when those policies are followed. The rules or policies in organizations, for instance, are intended behaviours that must be carried out by its employees. Hence, these promotes greater facilitation and coordination between staffs and the organization. Whereas, P2 and P8 answer the question based on their personal values which reflect the things they are providing the 
institution and their students. Many personal aspects interact to determine the actions of a person in a leadership role, such as their perceptions, behaviour, experience, commitment and skills. Bruno and Lay [25] explain that values will affect not only the perceptions of appropriate ends, but also the perceptions of the appropriate means to those ends. Additionally, participants $1,7,8$ and 12 state that ethical behaviour should be practiced in workplace conformity that promote leadership and serves as a role model. It denotes that servant leaders are the best role models. They weigh every actions and decisions that they are making in observance of values in the most ethical way.

After being asked on how the participants come up with their ethical decisions, P1, P6, P9 and P10, responded with adherence to the system or the policy of the institution. P1 believes that decisions should adhere to the system which he thinks has firm set of policies and procedures. P9 also come up with ethical decisions by complying with the manual for the students or faculty. According to Sanelli [26] policies and procedures are important component of any organization that they establish acceptable behaviour to be followed by the employees. They also ensure consistency in decision-making process.

On the other hand, P2, P3, P11, P14 agreed on checking for the facts first and having an investigation before coming up with the appropriate ethical decision. According to $\mathrm{P} 2$, different viewpoints must be considered for it is very important to come up with something that would be fair for all, thus, evaluating alternatives is very essential. P11 stressed the importance of having an investigation until everything is proven. It has been in any ethical framework to get the facts straight before evaluating the decision to be acted on. The second step after recognizing the ethical issue, as de Fine Licht [27] pointed out, is to know about the factors first before getting into the decision. Investigation is very much essential, and everything must be laid out on the table.

To P5 and P8, discussing the situation with others would help them identify the best ethical decision. They both shared that ethical decisions should not derive from one person only. It should come up in consultancy and consideration with the higher-ups, like the Dean or Academic Program Head. This is similar to the findings shared by Williams and Wehrman [28] that having the understanding of one another's ethical inputs can lead to a better understanding of what seems to be more cohesive decision to come up with. This could help one, broaden his or her perspective on the issue and be able to decide on a more sound and justified manner.

The last interview question about living out university X Core Values of Fortitude, Excellence, and Uprightness reveals seven relevant themes answered by twelve participants. Comprehensively, the theme which arose from the question is as follows: participant 1 made mention of allowing room for selfimprovement; participants 1, 2, and 5 mentioned their adherence to significant tasks; participant 1 remarked of non-toleration of plagiarism and cheating; participants $1,2,3$, and 11 made mention of strong protection of one's integrity; participants $4,5,6$, and 12 made mention of punctuality, attendance, professionalism, and adherence to policies; respondent 2 made mention of being unaffected of issues and accusations; and participants 4, 7, and 5 remarked of high respect to colleagues and students. Meanwhile, participants 7 and 11 remarked high regard to bring service to the community, participant 7 made mention of the importance of delivering good lessons so that values may be integrated always. Respondent 12 interestingly mentioned being prayerful, and Participant 13 stressed the importance of truly knowing the core values' meaning and living them out.

The Program head who made mention of giving importance to tasks believe that everything that is done with purpose and commitment would lead to excellence. Likewise, the virtue of Integrity which was mentioned repeatedly by the Program heads is seen as the ability to be upright despite challenges and forces that arise in the office. Punctuality and attendance, professionalism, Adherence to policies, which were also repeatedly discussed by the participants are seen as factors that contribute to one's uprightness and excellence.

In a nutshell, the participants' answers reflect the core values of Fortitude which is defined as the ability to remain steadfast despite trials and life's challenges, Excellence which is defined as a distinction derived from a job well done, and Uprightness which is the ability to behave in an honest way while observing high moral standards.

\section{Conclusion}

Academic program heads serve as one of the sources of influence in terms of ethical behaviour in an organization [29] [30]. Likewise, they are responsible when it comes to the norms and code of conduct that guide employees' behaviour [31] [32]. In addressing ethical practices of students and faculty, program heads always adhere to professional codes of conduct and institutional policies in order to come up with a sound decision that also mirrors the institution core values fortitude, excellence and uprightness. Dialogues and decision making in the department level are also observed to ensure fairness and to avoid conflict of interest.

The researchers studied examples of ethical behaviour of thirteen program heads who have written about ethics, using a descriptive approach in order to understand ethical behaviour and learn from it. After studying their behaviour, writings about ethical 
dilemmas and ethics they summarized the following common themes. All thirteen program heads demonstrate a strong commitment to perceive and interpret reality within the context of honesty and openness. The latter traits are particularly sought after in times of crisis when a program heads need to maintain. Next, program heads can create reality by continually reaffirming the ideals and beliefs of their respective organizations. They recognize that midlevel decision-making have huge impact in running an organization, particularly in the department level.

From the perspective of personality, program heads possess an exceptionally strong motivation and are emotionally strong, courageous, fair in treating all co-workers and students just and advocate temperance. They also value moral commitment which is rooted in their faith and belief that leads them to becoming a morally responsible leaders in their area. The determinants of highly ethical organization according to Pastin [33] include: 1) individuals who recognize and accept personal responsibility for the actions of the organization; 2) a profound devotion to fairness to other person; 3) being comfortable with interacting with external groups; 4) tying all activities in with an overall purpose. Program heads have an important role to play in implementing an organizational culture which Hitt refers to as clarifying values [29]. In fact, they were aware of the broader factors impacting on the university context that have been creating a fertile field in which dilemmas have been flourishing. This understanding was most clearly identified by most of the participants.

A strong theme in the study was the desire of academic leaders to uphold professional standards by being just in their dealings with students and staff. The program heads mentioned times when their professional values clashed with policies or procedures, they thought were unfair or inappropriate. Most of them responded that it is imperative to investigate first before deciding on an issue as well as appropriate decision -makings should properly done balancing the pros and cons of a decision they are about to make considering the rules and policies of the institution. The study also posits that ethical dilemmas in the university $\mathrm{X}$ were rare as there are strong rules in place'. This comment suggests that staff within that organization were aware of the rules and policies, and that those rules and policies were being followed.

\section{References}

[1] Weegar, M. A. (2007). Promoting ethical practices within institutions of higher education. In Proceedings of the 2007 Association for Business Communication Annual Convention. http://business communication.org/wpcontent /uploads/2011/04/31ABC07.pdf (Access Date: 18 May 2020).
[2] Mihelič, K. K., Lipičnik, B., and Tekavčič, M. (2010). Ethical leadership. International Journal of Management and Information Systems (IJMIS), 14(5). DOI: https://doi.org/1 0.19030/ijmis.v14i5.11.

[3] Catacutan, M. R. G., and de Guzman, A. B. (2015). Ethical decision-making in academic administration: A qualitative study of college deans' ethical frameworks. The Australian Educational Researcher, 42(4), 483-514. DOI: https://doi.org/10.1007/s13384-015-0179-y.

[4] Emery, E. (2017). Leadership, decision-making, and ethical behaviour. Journal of Business and Economic Policy, 4(1), 41-49.

[5] Al-Omari, A. A. (2008). The international leadership competencies of Jordanian universities leaders International Journal of Applied Educational Studies, 1(1).

[6] Dimmock, C. (2003). Leadership in learning centred schools: cultural context, functions and qualities. Leadership in education, 3-22. DOI: http://dx.doi.org/10.4 135/9781446215036.n1

[7] Simkins, T., Sisum, C., and Memon, M. (2003). School leadership in Pakistan: Exploring the headteacher's role. School Effectiveness and School Improvement, 14(3), 275 291. DOI: http://dx.doi.org/ 10.1076/sesi.14.3.275.15841

[8] Foster, W. (1986). Paradigms and promises: New approaches to educational administration. Buffalo, NY: Prometheus Books.

[9] Vogel, L. R. (2012). Leading with Hearts and Minds: Ethical Orientations of Educational Leadership Doctoral Students. Values and Ethics in Educational Administration, 10(1), 1-12.

[10] Northouse, P. G. (2010). Authentic leadership. Leadership theory and practice ( $5^{\text {th }}$ ed., pp. 205-239). Los Angeles, CA: Sage.

[11] Shapiro, J. P., and Stefkovich, J. A. (2005). Viewing ethical dilemmas through multiple paradigms. Ethical leadership and decision making in education: Applying theoretical perspectives to complex dilemmas, 10-26.

[12] Willis, J. W., Jost, M., and Nilakanta, R. (2007). Foundations of qualitative research: Interpretive and critical approaches. Sage.

[13] Arnett, J. L., Arnett, J. J., Feldman, S. S., and Cauffman, E. (2002). It's wrong, but everybody does it: Academic dishonesty among high school and college students. Contemporary Educational Psychology, 27(2) DOI: https://doi.org/10.1006/ce ps.2001.1088

[14] Carpenter, D. D., Harding, T. S., Finelli, C. J., and Passow, H. J. (2004). Does academic dishonesty relate to unethical behaviour in professional practice? An exploratory study. Science and engineering ethics, 10(2), 311-324.

[15] Ameen, E. C., Guffey, D. M., and McMillan, J. J. (1996). Accounting students' perceptions of questionable 
academic practices and factors affecting their propensity to cheat. Accounting Education, 5(3), 191-205. DOI: https://doi.org/10.1080/09639289600000020

[16] Kearney, C. A. (2008). School absenteeism and school refusal behaviour in youth: A contemporary review. Clinical psychology review, 28(3), 451-471. DOI: http://dx.doi.org/10.1016/j.cpr.2007.07.012.

[17] Bray, E. (2005). Codes of conduct in public schools: a legal perspective. South African journal of education, 25(3), 133-138.

[18] Barrett, D. E., Casey, J. E., Visser, R. D., and Headley, K. N. (2012). How do teachers make judgments about ethical and unethical behaviours? Toward the development of a code of conduct for teachers. Teaching and Teacher Education, 28(6), 890-898. DOI: https://doi.org/10.101 6/j.tate.2012.04. 003 .

[19] Rezaee, Z., Elmore, R. C., and Szendi, J. Z. (2001). Ethical behaviour in higher educational institutions: The role of the code of conduct. Journal of business ethics, 30(2), 171-183. DOI: https://doi.org/10.1023/ A:1006423220775.

[20] Mumthas, N. S., Munavvir, J., and Abdul Gafoor, K. (2014). Student and teacher perception of disciplinary practices: Types, reasons, consequences and alternatives. Online Submission, 2(4), 301-308.

[21] Lewis, R., Romi, S., Katz, Y. J., and Qui, X. (2008). Students' reaction to classroom discipline in Australia, Israel, and China. Teaching and Teacher Education, 24(3), 715-724. DOI: http://dx.doi.org/10.1016/j.tate.2007.05.0 03.

[22] Ehrich, L. C., Cranston, N., Kimber, M., and Starr, K. (2012). (Un)ethical practices and ethical dilemmas in universities: Academic leaders' perceptions. International Studies in Educational Administration, 40(2), 99-114.

[23] Sebisha, M. F. (2016). The implementation of a code of conduct in rural primary schools in Limpopo (Doctoral dissertation, University of Pretoria).

[24] Tyler, T. R. (2004). Promoting Employee Policy Adherence and Rule following in Work Settings-The Value of Self-Regulatory Approaches. Brook. L. Rev., 70, 1287.

[25] Bruno, L. F., and Lay, E. G. (2008). Personal values and leadership effectiveness. Journal of Business Research, 61(6), 678-683.

[26] Sanelli, A. (2018). The Importance of Policy and Procedure: A case study of an investigation and the policy and procedure shortcomings it revealed. Retrieved https://www.convercent.com/blog/the-importanceofpolicy-procedure.

[27] de Fine Licht, J. (2014). Transparency actually: how transparency affects public perceptions of political decisionmaking. European political science review, 6 (2), 309-330. DOI: https://doi.org/10.1017/S1755773913000131.
[28] Williams, R. L., and Wehrman, J. D. (2010). Collaboration and confidentiality: Not a paradox but an understanding between principals and school counselors. NASSP Bulletin, 94(2), 107-119. DOI: https://doi.org/10.1 $177 / 0192636510374229$.

[29] Hitt, W. D. (1990). Ethics and leadership: Putting theory into practice. Columbus: Battelle Press.

[30] Jansen, E., and Von Glinow, M. A. (1985). Ethical ambivalence and organizational reward systems. Academy of Management Review, 814-822. DOI: http://dx.doi.org/1 $0.2307 / 258049$

[31] Bennis, W., and Nanus, B. (1985). Leadership: The strategies for taking charge: New York: Harper and Row.

[32] Cyert, R. M. (1990). Defining leadership and explicating the process. Nonprofit Management and Leadership, 1(1), 29-38. DOI: https://doi.org/10.100 2/nml.4130010105

[33] Pastin, M. (1986). The hard problems of management: Getting the Ethics Edge. Los Angeles: Jossey-Bass Publ.

[34] Strike, K. A. (1991). Chapter 9: The Moral Role of Schooling in a Liberal Democratic Society. Review of research in education, 17(1), 413483. DOI: https://doi.org/1 0.3102/0091732X01 7001413.

[35] Cavanagh, G. F., Moberg, D. J., and Velasquez, M. (1981). The ethics of organizational politics. Academy of Management Review 6, 363-374. DOI: https://doi.org/10.5 465/amr.1981.4285767.

\section{Acknowledgements}

We would like to thank, Dr. Arnel Bravo, Director of General Education at Far Eastern University, Manila, for assisting and guiding us to complete this study. To all FEU-IE faculty and staff headed by Dr. Harold John Culala, Dean of the Institute of Education, thank you all for your endless support. 